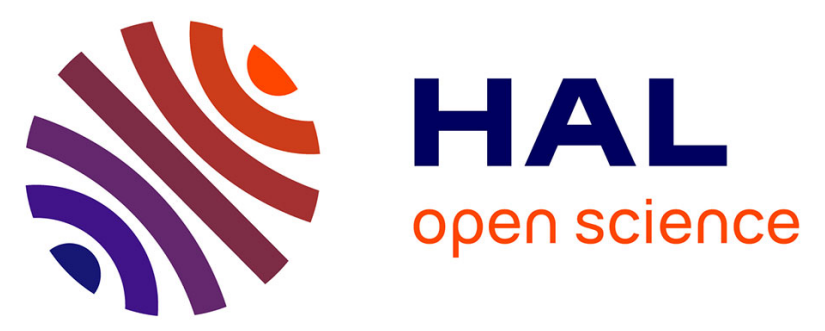

\title{
Simultaneously increasing the hydrophobicity and interfacial adhesion of carbon fibres: a simple pathway to install passive functionality into composites
}

Chantelle L Arnold, Daniel J Eyckens, Linden Servinis, Mark D Nave, Huaying Yin, Ross Marceau, Jean Pinson, Baris Demir, Tiffany Walsh, Luke

C Henderson

\section{To cite this version:}

Chantelle L Arnold, Daniel J Eyckens, Linden Servinis, Mark D Nave, Huaying Yin, et al.. Simultaneously increasing the hydrophobicity and interfacial adhesion of carbon fibres: a simple pathway to install passive functionality into composites. Journal of Materials Chemistry A, 2019, 7 (22), pp.13483-13494. 10.1039/c9ta02436k . hal-02342144

HAL Id: hal-02342144

https://hal.science/hal-02342144

Submitted on 31 Oct 2019

HAL is a multi-disciplinary open access archive for the deposit and dissemination of scientific research documents, whether they are published or not. The documents may come from teaching and research institutions in France or abroad, or from public or private research centers.
L'archive ouverte pluridisciplinaire HAL, est destinée au dépôt et à la diffusion de documents scientifiques de niveau recherche, publiés ou non, émanant des établissements d'enseignement et de recherche français ou étrangers, des laboratoires publics ou privés. 
Check for updates

Cite this: DOI: 10.1039/c9ta02436k

\section{Simultaneously increasing the hydrophobicity and interfacial adhesion of carbon fibres: a simple pathway to install passive functionality into composites $\uparrow$}

\author{
Chantelle L. Arnold, ${ }^{a}$ Daniel J. Eyckens, ${ }^{a}$ Linden Servinis, ${ }^{a}$ Mark D. Nave, ${ }^{a}$ Huaying Yin, ${ }^{a}$ \\ Ross K. W. Marceau, (D) ${ }^{a}$ Jean Pinson, (D) ${ }^{b}$ Baris Demir, ${ }^{a}$ Tiffany R. Walsh (D) ${ }^{a}$ \\ and Luke C. Henderson (D) *a
}

Received 5th March 2019 Accepted 7th April 2019

DOI: $10.1039 / c 9 t a 02436 k$

rsc.li/materials-a

\begin{abstract}
A common strategy to enhance the fibre-to-matrix adhesion of carbon fibres is to increase the surface polarity using extensive and harsh oxidation techniques. In this work, we use a novel and scalable strategy to significantly increase the hydrophobicity of carbon fibres without any sacrifice in the fibres' physical properties and demonstrate simultaneous increases to the fibre-to-matrix adhesion (59-216\%). These findings contradict the commonly accepted paradigm of high fibre polarity correlating to increased interfacial adhesion. We demonstrate the ability to covalently modify the surface of carbon fibres through electrochemical reduction of nitroaryldiazonium salts to generate perfluorinated alkyl radicals. Surface modification was confirmed by XPS, ATRIR, and TEM. The surfaces produced are highly hydrophobic, though this may be mitigated through the reduction of nitro groups to amines, or increased through the accumulative effects of perfluoroalkyl chains and nitro groups (WCA ranges from $99.9 \pm 0.4^{\circ}$ up to $135.5 \pm 0.2^{\circ}$, versus pristine fibre $98.4 \pm 0.6^{\circ}$ ). Hydrophobic fibres functionalized only with perfluoroalkyl groups were stable to both acidic $(\mathrm{pH} 1)$ and basic $(\mathrm{pH} 12)$ environments. All surface chemistries demonstrated comparable or improved interfacial shear strength and these results correlated well with calculated values of interfacial shear stress, determined via molecular dynamics simulations.
\end{abstract}

\section{Introduction}

Carbon fibre reinforced polymers (CFRP) are becoming a common alternative to traditional materials such as metals in automotive, maritime, and aerospace applications. These composite materials offer high strength, light weight, and great versatility of design. Thus they offer vast potential in weight reduction of mass transport vehicles, thereby increasing fuel efficiency, corresponding to a decrease in $\mathrm{CO}_{2}$ emissions. The surface chemistry of carbon fibres dictates, to a large extent, the overall performance of a CFRP. The interface where the fibres and resin meet allows for the transfer of stress/load between the relatively soft matrix and stiff fibres and is a common place of failure. ${ }^{1-5}$

There have been considerable efforts in the manipulation of carbon fibre surface chemistry to increase the fibre-to-matrix adhesion using wet chemical oxidation, electrochemistry, plasma, and ozone, among others. ${ }^{6-9}$ There is a substantial body

${ }^{a}$ Deakin University, Institute for Frontier Materials, Waurn Ponds, Victoria 3216, Australia.E-mail: luke.henderson@deakin.edu.au

${ }^{b}$ Sorbonne Paris Cite, Université Paris Diderot, ITODYS, UMR 7086 CNRS, 15 rue J-A de Baïf, 75013 Paris, France

$\dagger$ Electronic supplementary information (ESI) available: XPS, SEM images, and detailed MD procedures are provided. See DOI: 10.1039/c9ta02436k of work which proposes that increasing the hydrophilicity (or surface polarity) of carbon fibres correlates to enhanced interfacial adhesion. ${ }^{\text {9-14 }}$ This correlation has permeated the composite literature and is born from the idea that polar functional groups, such as carboxylic acids $(\mathrm{COOH})$, ketones $(\mathrm{C}=\mathrm{O})$, phenols $(\mathrm{PhOH})$, and other oxygenated species, facilitate efficient 'wet-out' of the fibres by the supporting polymer. Additionally, it has been proposed that these polar functional groups serve as reactive points to enable cross-linking between the resin and fibres. As such, over the past 30 years the correlation of a highly polar surface and superior interfacial adhesion has been firmly reinforced in the literature.

Following on from the original work, ${ }^{15}$ recent efforts by our group have shown the covalent modification of carbon fibre surfaces through the use of aryldiazonium salts under reductive electrochemical conditions. ${ }^{\mathbf{1 6 - 2 0}}$ This can be achieved rapidly, and reliably to introduce a diverse range of surface chemistries complementing the intended supporting polymer resin.

To this end, there is substantial interest in developing carbon fibres that go beyond structural reinforcement and provide additional value to a composite, either from a functional (e.g. self-healing), technical (e.g. micro crack detection), or passive (e.g. minimizing water uptake) perspective. 
A recent review by $\mathrm{Si}$ and $\mathrm{Guo}^{21}$ states that the two largest hurdles preventing hydrophobic surfaces from being widespread in their application are (1) large scale preparation, and (2) the binding strength between the hydrophobic coating and the substrates. The focus of the work presented here is the rapid generation of hydrophobic carbon fibres, a material produced on a massive scale, via covalent surface modification, thus addressing these two issues.

Surfaces possessing hydrophobicity have found widespread use across a huge variety of industries and in everyday items (e.g. cookware, tooling, etc.). Due to this broad utility, methods to generate hydrophobic surfaces have gained immense interest over the past decade. ${ }^{22-26}$ These materials offer abundant potential in water transport, self-cleaning, anti-corrosion, drag reduction, oil-and-water separation, and anti-biofouling properties, among other applications..$^{22-25,27,28}$ The generation of a hydrophobic surface can be carried out several ways, with two approaches being the most common.

The first is naturally inspired, relying on nano-roughening to achieve a 'lotus-leaf' effect, and has been carried out extensively on carbonaceous surfaces using a variety of techniques, ${ }^{25,26}$ including the deposition of carbon nanotubes, graphene, carbon nanofibres, etc. The second approach uses intermolecular interactions via the installation of non-polar alkyl groups onto the surface of the material, of which perfluorinated materials are a common choice of deposition agent. ${ }^{28}$

While useful, the experimental conditions required to install either of these surface topologies or chemistries, respectively, are not typically conducive to large scales, requiring a large investment of time and energy. Of particular note, the latter approach can involve the use of gaseous fluorinated molecules that present serious environmental concerns.

Additionally, these treatments are not typically carried out on carbon fibres (as distinct entities from carbon nanofibres, nanotubes, etc.), and to the best of our knowledge no report exists in the literature on how the induced hydrophobicity effects fibre-to-matrix adhesion. A primary concern, and potential disincentive, being that hydrophobic fibres will poorly adhere to the polymer matrix, thus decreasing interfacial shear strength (IFSS).

It is already known that the interfacial adhesion of carbon fibres to the supporting resin is one of the largest contributors to the overall performance of the composite material, and improving this interaction either chemically or physically has been a very active area of research for more than 25 years. ${ }^{2,3,14,29}$

In 2007, Bismarck et al. ${ }^{6}$ reported the use of a plasma treatment for fluorination of PAN-based carbon fibres using a $\mathrm{N}_{2}$ and $\mathrm{CHClF}_{2}$ gas mixture. An increase in dispersive forces on the fibre surface were measured using dynamic contact angle.

Recently reported by Hetemi et al. was the ability to attach alkyl groups, including perfluorinated compounds, to the surface of glassy carbon electrodes. ${ }^{30}$ The method used in that work involved a sacrificial aryl radical arising from the reduction of 2,6-dimethylbenzene diazonium tetrafluoroborate $\mathbf{1}$. This sterically demanding radical (2) does not react with the surface but is able to abstract an iodine atom from an alkyl halide, to give an alkyl radical 3, allowing for the attachment of these alkyl chains to the electrode surface (Fig. 1). This was extended further by creating mixed films on the surface of the electrodes by using a combination of aryldiazonium salts (such as 4-nitrobenzenediazonium tetrafluoroborate 4) and alkyl iodide 5, both compounds lead to radicals (4-nitrophenyl and perfluoroalkyl, respectively) that compete for reaction with the surface and the growing film. ${ }^{31}$

Reported here, is the successful application of taking these mixed surface chemistries from small glassy carbon electrodes to carbon fibres. Using this methodology, a range of surface modifications were planned for this work, ensuring that a crosssection of surface effects could be examined (Fig. 2). The series of surfaces that were envisioned for this study are simplified below; Surface 1 consists of multi-layers grown on the surface using 4-nitrophenyldiazonium tetrafluoroborate 4. This surface provides molecules that are grafted to the material, but not able to covalently cross-link with an epoxy resin due to the high oxidation state nitrogen.

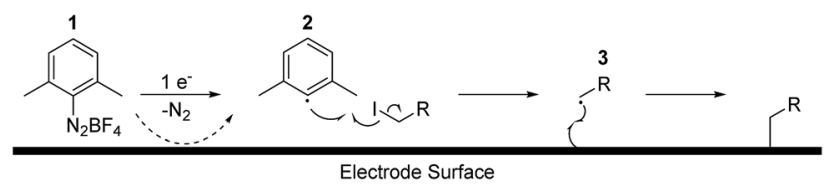

Fig. 1 Use of a sacrificial diazonium salt 1 as a means to generate alkyl radicals 3 for electrode modification.

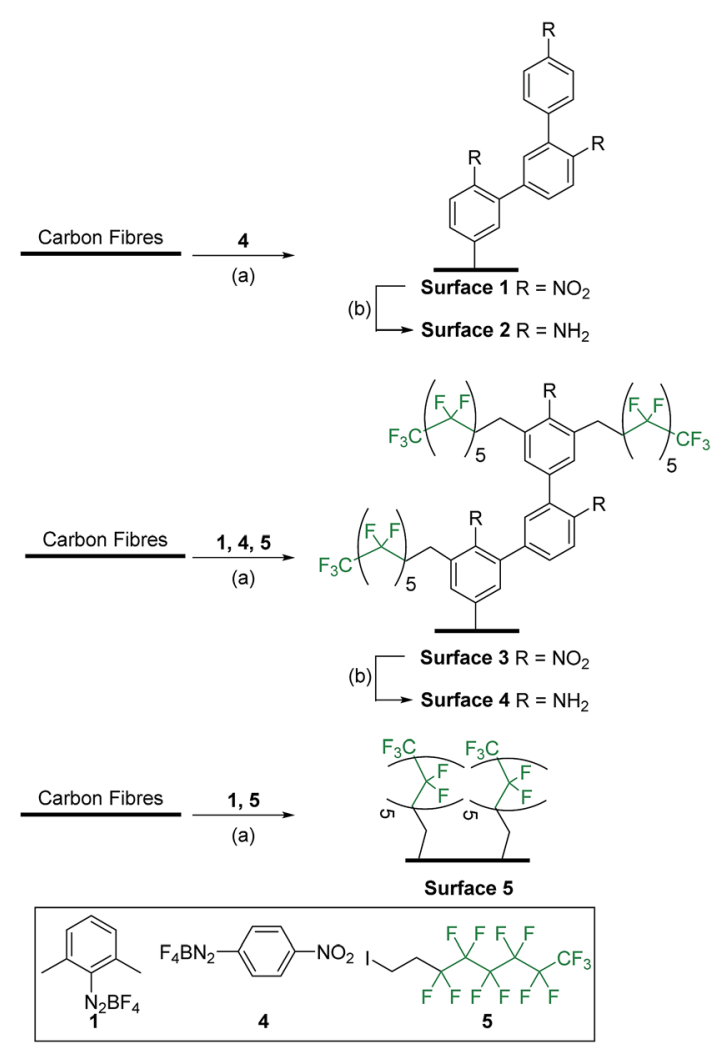

Fig. 2 Simplified representative structures of the surface chemistries to be fabricated in this study; (a) $1.0 \mathrm{MTBAPF}_{6}$ in $\mathrm{MeCN}_{1}-0.5 \mathrm{~V}$ (vs. Ag/ $\mathrm{AgCl}$ ), sweep rate of $10 \mathrm{mV} \mathrm{s}^{-1}$ r.t., $10 \mathrm{~min}$; (b) $0.1 \mathrm{M} \mathrm{KCl}$ in $\mathrm{EtOH}: \mathrm{H}_{2} \mathrm{O}$ (1: 9), r.t., $-1.0 \vee(v s . \mathrm{Ag} / \mathrm{AgCl}), 10 \mathrm{~min}$. 
Electrochemical reduction of these aryl nitro moieties provides Surface 2, now able to examine cross-linking phenomena at the fibre-to-matrix interface. Carrying out this same reduction process in the presence of 2,6-dimethylphenyldiazonium tetrafluoroborate $\mathbf{1}$ and perfluorinated iodide $\mathbf{5}$ should give a similar aryl multi-layer surface which has also been decorated with the perfluorinated species, Surface 3 . Again, this provides a non-reactive surface, with respect to epoxy, and thus a similar reduction can be carried out to access the nucleophilic anilinic analogue (Surface 4). Finally, the last surface chemistry envisaged was the direct attachment of the perfluoroalkyl species to the fibre surface, in the absence of any phenyl multi-layer, thus allowing us to determine the role on IFSS for each scenario (Surface 5).

Herein we report the successful surface modification of carbon fibres with homogeneous and mixed surface chemistries and report the effects on interfacial shear strength using an epoxy matrix. Additionally, fibres that possessed a mixture of perfluoro and nitrophenyl groups exhibit hydrophobic properties (determined via water contact angle), substantial gains to interfacial shear strength, and were resistant to corrosive environments (acid and alkaline). The modification process takes 10 minutes, using milder potentials than those used during fibre manufacture, and can be applied to carbon fibre tows (i.e. during manufacture) or woven fabrics (after manufacture). We have used TEM to show that the layer of fluorinated species on the surface of the fibre is very thin (approx. $<30 \mathrm{~nm}$ ) and molecular dynamics simulation has been used to interrogate the fibre-matrix interface to substantiate experimental results.

\section{Experimental}

Carbon fibre samples (unsized, unoxidised fibre) were supplied by and carbonised in-line at Carbon Nexus at Deakin University (Australia). These fibres served as the control fibre for all experiments, they were handled and treated identically to functionalised fibre. Chemicals, reagents and solvents were purchased from Sigma-Aldrich (Australia) and used as received.

\section{Representative fibre functionalisation procedure}

All tows of carbon fibre were connected to a potentiostat (Metrohm PG-stat) via conductive copper tape. They were immersed in an acetonitrile solution of diazonium salts $\mathbf{1}$ and $\mathbf{4}$, and alkyliodide 5 in the quantities outlined below with TBAPF $_{6}(0.1$ M) supporting electrolyte. A potential of $-0.5 \mathrm{~V}$ was applied to the carbon fibre working electrode ( $v s$. $\mathrm{Ag} / \mathrm{AgCl}$ ) for 10 minutes. The fibres were then removed and washed sequentially with chloroform, dichloromethane, ethanol, and acetone, then dried under vacuum to remove residual solvent.

Surface 1: diazonium 4 (50 mM), $5(0 \mathrm{mM})$

Surface 3: diazonium 4 (50 mM), 5 (200 mM)

Surface 5: diazonium 1 (50 mM), 5 (200 mM)

Surfaces 2 and 4 were generated by electrochemical reduction $\left(\mathrm{H}_{2} \mathrm{O} / \mathrm{EtOH}, 0.1 \mathrm{M} \mathrm{KCl}\right)$ of Surfaces 1 and 3, respectively. The fibres were connected to the potentiostat (Metrohm-PG stat) via conducting copper tape and the potential varied from
-1.5 to $0.5 \mathrm{~V}$ (vs. $\mathrm{Ag} / \mathrm{AgCl})$ at a scan rate of $10 \mathrm{mV}$ per second, repeated for 6 scans. The fibres were then removed and washed sequentially with chloroform, dichloromethane, ethanol, and acetone, then dried under vacuum to remove residual solvent.

\section{Determination of water contact angle}

Due to the large contact angles observed in this work, the typical process of using a Wilhelmy plate method to determine advancing and receding contact angles was not possible. Attempts to advance the fibres into the water caused them to deflect from the water surface rather than be wetted by the solution. As such, short lengths $(\sim 5 \mathrm{~cm})$ of each treated fibre was taken, were taped to a glass microscope slide under tension. While every effort to ensure a flat surface was generated to measure the WCA accurately, the curved nature of the fibre may provide some inconsistencies between samples. Thus, these values are provided to indicate trends of hydrophobicity/ hydrophilicity between treatments rather than for quantitative comparison. The contact angles reported are the average of 30 measurements, with one measurement taken each second, starting 3 seconds after the drop was placed on the fibre bundle. Note that no droplet bouncing, or the formation of droplet satellites were observed in any case. The errors reported are the standard deviation of all measurements taken.

\section{TEM sample preparation}

The sample for TEM was prepared using a lamella lift-out method from the cross-section of an individual carbon fibre, with an FEI Quanta 3D field-emission gun (FEG) dual-beam focussed ion beam/scanning electron microscope (FIB/SEM) instrument utilising a Ga${ }^{+}$ion source. A thin platinum layer ( 100 $\mathrm{nm}$ thick) was deposited with the electron beam $(5 \mathrm{kV}, 53 \mathrm{pA})$ to protect the surface of the fibre before exposure to the ion beam. The platinum layer was then built up to a thickness of approximately $3 \mu \mathrm{m}$ with ion beam deposition ( $30 \mathrm{kV}, 50 \mathrm{pA}$ ) prior to milling. Ion beam milling was carried out at $30 \mathrm{kV}$ using currents ranging from 10 $\mathrm{nA}$ down to $100 \mathrm{pA}$. Glancing angle ion beam cleaning steps $(5 \mathrm{kV}$, $48 \mathrm{pA}, \pm 5^{\circ}$ and $2 \mathrm{kV}, 27 \mathrm{pA}, \pm 7^{\circ}$ ) were used to minimise ion beam damage surface layers on the final specimen.

TEM of the lamella sample prepared by FIB-SEM was conducted using a JEOL JEM 2100F FEG TEM instrument operated at $200 \mathrm{kV}$. EELS was carried out using a Gatan Quantum energy filter and spectrometer, under both TEM and STEM modes.

\section{SEM sample preparation}

Onto a carbon tape covered stub a $0.5 \mathrm{~cm}$ cutting of carbon fibre was deposited, followed by a $5 \mathrm{~nm}$ coating of gold using a Leica ACE600 instrument. The samples were then visualized using a Zeiss Supra 55VP FEG SEM.

\section{Determination of interfacial shear strength}

Initially, the tensile strength and Young's modulus was determined for each of the treated fibres. Samples were tested on a Favimat+ single fibre tester (Textechno H. Stein), automatically recording force extension data for individual fibres loaded into 
a magazine (25 samples), normalized via linear density determined by vibroscope. Each filament was pre-tensioned $(\sim 100-$ $150 \mathrm{mg}$ ) prior to extension. Tensile load-extension curves were collected at $1 \mathrm{~mm} \mathrm{~min}^{-1}$ using a gauge length of $25 \mathrm{~mm}$. The mean values of linear strength and Young's modulus were determined. As the statistical distribution of carbon fibre strength is described by a weakest link model, the data were also analyzed by the two-parameter Weibull probability $(P)$ equation:

$$
P=1-\exp \left[-\left(\frac{\sigma}{\sigma_{0}}\right)^{m}\right]
$$

where $P$ is the cumulative probability of failure of a carbon fibre at applied tensile strength. The parameters of Weibull shape parameter $(\sigma)$, and Weibull modulus $(m)$, is not a physical parameter but describes the distribution, were calculated. $P$ is determined for each point using the median rank method:

$$
P=\frac{i-0.3}{n+0.4}
$$

where $n=$ no. of sample points and $i$ is the rank. Rearrangement of the probability expression to a straight-line form allows $m$ and $\sigma_{0}$ to be obtained by linear regression.

\section{Fabrication of single filament composite dog-bone samples}

Five single filament composite samples were prepared for each surface chemistry synthesised by the reported methodology. This was carried out by placing a single filament within the centre of a dog-bone shaped mould followed by pre-tensioning at each end (100 $\mathrm{mg}$ at each end). An epoxy resin combination (RIM935/RIM937) in a $10: 4 \mathrm{w} / \mathrm{w}$ ratio as recommended by manufacturer was prepared and poured into the mould.

The epoxy was cured at room temperature for 48 hours and post cured for an additional 12 hours at $100{ }^{\circ} \mathrm{C}$. The final sample dimensions were $25 \mathrm{~mm} \times 5 \mathrm{~mm} \times 1.5 \mathrm{~mm}$ (length $\times$ width $\times$ depth).

The samples were extended at a rate of $0.05 \mathrm{~mm} \mathrm{~min}^{-1}$ for 40 minutes in a tensile tester ( $30 \mathrm{kN}$ load cell) to give fragment saturation (Instron 5967, Instron Pty Ltd, USA). The fragments measured using a calibrated optical microscope (Olympus BX51M) equipped with Olympus DP70. The critical fibre length $\left(l_{\mathrm{c}}\right)$ was determined using:

$$
l_{\mathrm{c}}=\frac{4}{3} l
$$

where $l$ is the average fragment length as measured using the optical microscope after extension to fibre saturation, and $l_{\mathrm{c}}$ is the critical length. Using the Weibull modulus $m$ and the characteristic strength $\sigma_{0}$ at gauge length $L_{0}$, the characteristic strength at critical length $\sigma_{\mathrm{f}}\left(l_{\mathrm{c}}\right)$ can be calculated.

$$
\sigma_{\mathrm{f}}\left(l_{\mathrm{c}}\right)=\sigma_{0}\left(L_{0}\right)\left(\frac{L_{0}}{l_{\mathrm{c}}}\right)^{\frac{1}{m}}
$$

Finally, using the average fibre diameter $d$ (averaged to 7 $\mu \mathrm{m})$, the apparent interfacial shear strength $\tau$ can be calculated using the following equation:

$$
\tau=\frac{\sigma_{\mathrm{f}}\left(l_{\mathrm{c}}\right) d}{2 l_{\mathrm{c}}}
$$

This value was calculated for each of the surfaces generated in this work and the pristine fibre sample. Depending on the degree of interfacial adhesion possessed by each sample, up to 60 fragments can be present within each specimen giving a total of 200-300 fragments for each surface chemistry installed using this methodology. This high level of data provides a good degree of confidence for the IFSS reported herein.

\section{Molecular dynamics procedures}

All molecular dynamics simulations were performed using the LAMMPS software package (http://lammps.sandia.gov), ${ }^{32}$ with a time-step of $1 \mathrm{fs}$, and periodic boundary conditions implemented in all three principal directions. Temperature and pressure control were exerted via use of the Nosé-Hoover thermostat $^{33}$ and barostat, ${ }^{34,35}$ respectively. We used the all-atom DREIDING force-field ${ }^{36}$ to model to describe all interatomic interactions in our system. Following our earlier work, ${ }^{37,38}$ the carbon fibre surface was approximated via use of a 3-layer graphite substrate. The lateral dimensions of our graphite slab (and thus our simulation cell) were $127.8 \times 147.6 \AA$. The polymer matrix was modelled using EPON-862 (diglycidyl ether of bisphenol F) and DETDA (diethyl toluenediamine) in a ratio of $2: 1$. Using our in situ dynamic computational cross-linking procedure, $^{37,38}$ reactive atomic sites of these two molecules were computationally cross-linked in the presence of the grafted fibre surface to form a $3 \mathrm{D}$ polymer network. Five different surfaces were modelled. Surfaces 2 and $\mathbf{4}$ were modelled to be reactive with respect to chemical cross-link formation with the polymer molecules. Surfaces 1, 3 and $\mathbf{5}$ were modelled as unreactive towards the formation of chemical cross-link bonds with the polymer molecules. Following the generation of our cross-linked functionalized interfacial structures, we then performed non-equilibrium substrate pull-out simulations on these interfaces to determine the interfacial shear stress. Full details of all aspects of the molecular simulations, and analyses of the simulation data, are provided in the ESI. $\dagger$

\section{Results and discussion}

\section{Modification of the carbon fibre surface}

The modification of unsized carbon fibres was conducted using a standard three-electrode cell as is consistent with our previous work on the electrochemical surface modification. ${ }^{39}$ Using a reported literature procedure ${ }^{\mathbf{3 0 , 3 1}}$ the fibres were functionalized using chronoamperometry, at a potential of $-0.5 \mathrm{~V}$ (vs. $\mathrm{Ag} / \mathrm{AgCl})$ for 10 minutes. A selection of the fibres containing nitrophenyl groups (Surface 1) were resubmitted to electrochemical reduction to convert the nitrophenyl groups to the corresponding aniline groups (Surface 2). In each case, the fibres were removed from the electrochemical solution and thoroughly washed with chloroform, ethanol, dichloromethane, and acetone then dried under high vacuum for 2 days at room temperature. It is worth noting that this treatment time of 10 minutes, and the 
potentials used, are within the standard manufacturing window of the electrochemical surface treatments currently employed by the carbon fibre manufacturing industry. While this proof-ofconcept study has performed the surface modification in a batch process, the potential for transference of this method to an in-line process is very high.

\section{Characterisation of carbon fibres}

The functionalized fibres were then analysed by XPS to determine if their surface chemistry was consistent within treatments and proposed surface modifications (see ESI†). In all cases the XPS was consistent with the expected chemistry (see Table SI $1 \dagger$ for a more detailed description of the XPS spectra). All the survey spectra indicate the presence of C 1s (282-296 eV) and $\mathrm{O} 1 \mathrm{~s}(532-533 \mathrm{eV})$. The $\mathrm{C} 1 \mathrm{~s}$ corresponds to the contributions of the carbon fibres and the coating film. The $\mathrm{C} 1 \mathrm{~s}$ peak of all samples can be deconvoluted into three contributions at 285, $287,289 \mathrm{eV}$ corresponding, respectively, to aromatic carbons from the carbon fibre and the aromatic groups of the coating, to $\mathrm{C}-\mathrm{O}$ and $\mathrm{C}(=\mathrm{O}) \mathrm{OH}$ functions on the surface of the fibre (also observed on bare carbon fibres). In addition, the XPS spectra of Surfaces 3 and 5 present different contributions that can be assigned to the perfluoro chain, in particular at 292 and $294 \mathrm{eV}$ corresponding to $\mathrm{CF}_{2}$ and $\mathrm{CF}_{3}$ (16.8 and $3.4 \%$ for Surface 5), respectively.

The $\mathrm{O}$ 1s peak can be assigned to some contamination, to the presence of oxygenated groups on the surface of the carbon fibres ( $\sim 3 \%$ on a bare carbon fibre) $)^{20}$ and to the presence of nitro groups for Surfaces 1 and 3. The XPS spectrum of Surface 1 shows the presence of $\mathrm{N} 1 \mathrm{~s}(3.0 \%)$ with three components at 400,402 and $406 \mathrm{eV}$ that can be assigned respectively to (i) contamination and the presence of azo groups inside the film, ${ }^{14}$ (ii) protonated nitrogen and (iii) nitro groups $(1.4 \%)$. The spectrum of Surface 3 shows the presence of N 1s (3.8\%) with three components as Surface 1 including a contribution at $406 \mathrm{eV}(1.7 \%)$ corresponding to the nitro group and F $1 \mathrm{~s}(689 \mathrm{eV}$, $22.8 \%$ ) corresponding to the perfluoro chain. For Surfaces 2 and 4 the main component of nitrogen is located at $400 \mathrm{eV}$ corresponding to the amino groups but some residual nitrophenyl groups remained (identified by the XPS peak at $406 \mathrm{eV}$ ). The presence of these nitro groups was attributed to the generation of multilayers that render nitrophenyl groups electrochemically silent by lack of solvation, a phenomenon observed in thin films of aromatic groups previously. ${ }^{40}$

Finally, modified Surface 5 presents some nitrogen $(1.2 \%$ likely the same as that found on pristine carbon fibre) and F 1s (4.5\%), and the $\mathrm{C} 1 \mathrm{~s}$ peak presents a number of contributions, from which those at 294 and $292 \mathrm{eV}$ correspond to the terminal $\mathrm{CF}_{3}$ and the $\mathrm{CF}_{2}$ groups of the perfluoro chain. Thus, the XPS is in agreement with the expected surface chemistries.

Complementing this analysis, Attenuated Total Reflectance Infrared Spectroscopy (IRATR) supported the successful grafting of the fibres. The spectrum of Surface 1 compared to that of neat nitrobenzene (Fig. 3) shows the two peaks at 1513 and $1341 \mathrm{~cm}^{-1}$ on the spectrum of Surface 1 correspond to the antisymmetric and symmetric vibrations of the nitro group observed at 1522 and $1345 \mathrm{~cm}^{-1}$ for nitrobenzene, though a slight shift is present due to deposition of the former on the fibre surface (Fig. 3a, highlighted in blue boxes).

After reduction of the surface nitrophenyl groups, some of the nitrophenyl signals are still present, but an intense peak appears at $1597 \mathrm{~cm}^{-1}$ that can be assigned to the $\mathrm{NH}_{2}$ deformation of the aminophenyl groups (by comparison, aniline gives a peak at $1601 \mathrm{~cm}^{-1}$ ). Perfluoroalkyl chains present complex spectra between 1100 and $1300 \mathrm{~cm}^{-1}$ as exemplified in Fig. 4 for compound $5\left(1237,1199,1147 \mathrm{~cm}^{-1}\right) .^{41}$ The spectrum of Surface 5 is similar $\left(1247,1216,1149 \mathrm{~cm}^{-1}\right)$ indicating the presence of the perfluoro- chain on the carbon fibre surface.

When both compounds $\mathbf{4}$ and $\mathbf{5}$ are grafted on carbon fibres (Surface 3), both the nitrophenyl and the perfluoro- groups can be observed in the IR spectrum (1526, 1347 and 1242, 1219, $1147 \mathrm{~cm}^{-1}$, respectively), as shown in Fig. 4 . With these data suggesting successful modification of fibre surface, attention turned to assessing the strength of the adherence of these compounds to the fibre surface.

Analysis by thermogravimetric analysis (TGA) (in air, Fig. 5) can be compared to the results of other aryl-substituted carbonaceous surface. Reduced graphene oxide sheets modified or not with nitrophenyl groups begin burning at $\sim 20{ }^{\circ} \mathrm{C}$ and the mass loss reaches $24 \%$ and $7 \%$ at $800{ }^{\circ} \mathrm{C}$ for modified and not modified, respectively. ${ }^{42}$ Chlorophenyl modified carbon nanotubes show two different mass losses at 200$300{ }^{\circ} \mathrm{C}$ and $450-550{ }^{\circ} \mathrm{C}$ relative to the control. ${ }^{43}$ The TGA of nitrophenyl modified carbon black is also characterized by two processes at about $100-200{ }^{\circ} \mathrm{C}$ and $360-500{ }^{\circ} \mathrm{C}$ prior to the carbon burn-off.

The two weight losses are attributed to the decomposition and cleavage of the nitrophenyl organic groups, followed by material degradation. ${ }^{44}$ In this instance, unmodified carbon fibres are stable until approximately $900{ }^{\circ} \mathrm{C}$ followed by a slight
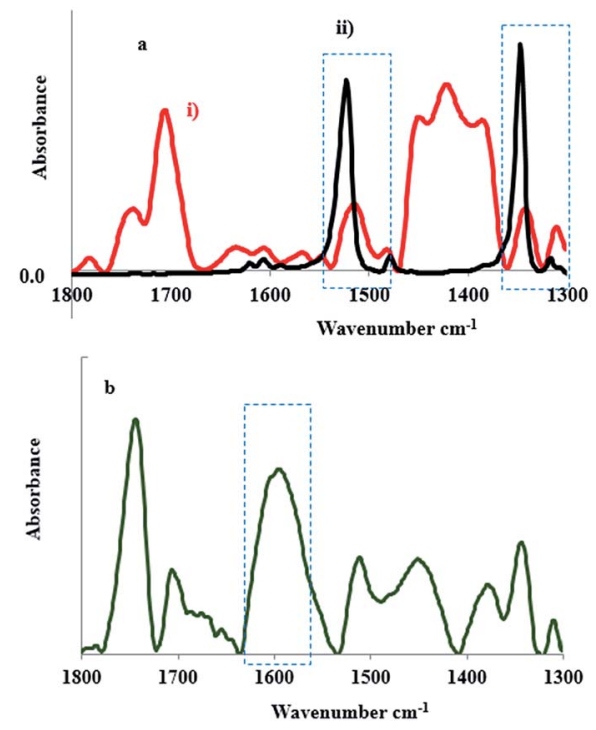

Fig. 3 (a) (i) IRATR spectrum of Surface 1, (ii) IRATR spectrum of nitrobenzene. (b) IRATR spectrum of Surface 2. Normalized spectra, arbitrary absorbance units. 

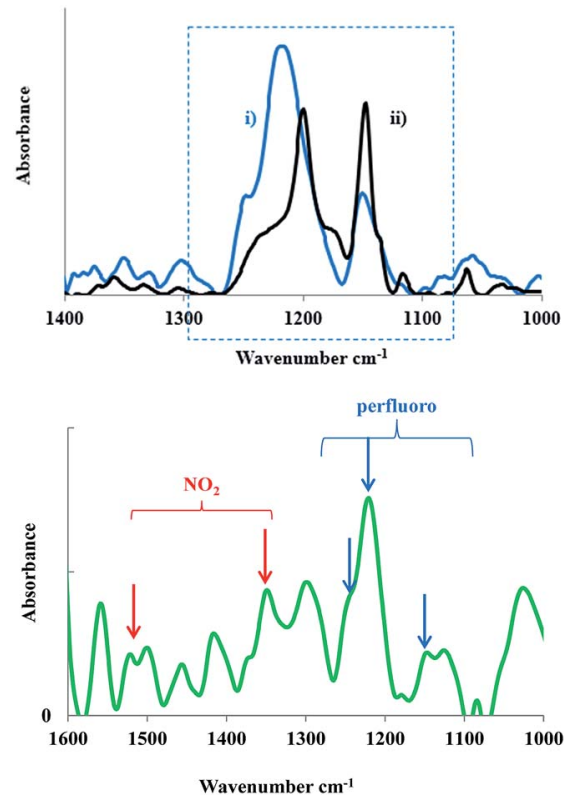

Fig. 4 Top: (i) IRATR spectrum of Surface 5, (ii) IRATR spectrum of compound 5. Normalized spectra, arbitrary absorbance units; Bottom: presence of nitro and fluorinated species on the fibre surface.

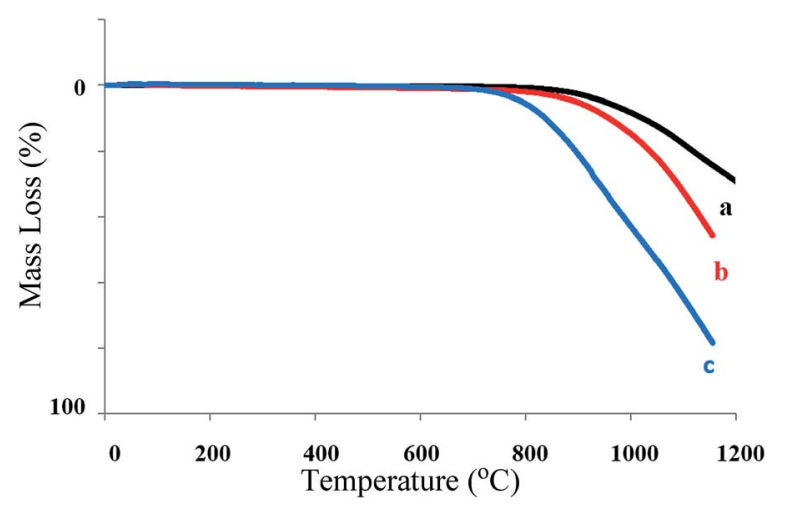

Fig. 5 TGA in air of (a) unmodified carbon fibre (black), (b) modified carbon fibres Surface 1 and (c) Surface 5.

decline as temperatures exceed $1000{ }^{\circ} \mathrm{C}$. Surface 1 , modified by aryl nitro groups shows a very similar behaviour though mass loss is initiated at a slightly lower temperature $\left(\sim 850{ }^{\circ} \mathrm{C}\right.$, Fig. 5, red curve). This suggests that the surface modified layer is degrading at this point, followed by material degradation, paralleled in the control sample. The initial degradation of Surface $\mathbf{5}$, possessing only perfluorinated species, is distinctly lower at $700{ }^{\circ} \mathrm{C}$ (Fig. 5, blue curve). Again, in this instance, the inclusion of more non-aromatic organic groups are likely to degrade at a lower temperature, followed by the underlying material. It is worth noting that while modification of these surfaces does initiate mass loss at lower temperatures, it is not likely that temperatures of this magnitude will be experienced during composite manufacture or service. Additionally, these temperatures of mass loss initiation suggest that the small organic molecules are covalently bound to the surface as adsorbed material would burn off at much lower temperatures.

\section{Determination of water contact angle (WCA) of treated fibres}

The determination of water contact angle for fibre tows is very difficult as they do not provide a perfectly flat surface for analysis, the use of dynamic contact angle via penetration of the fibre into water is not possible here, due to the hydrophobicity of the fibres (vide infra). Regardless, the sessile drop method is commonly carried out on surfaces to characterize their hydrophilicity/hydrophobicity and trends can be drawn from this. Using $3 \mu \mathrm{L}$ deionized water droplets, the contact angle for each surface, and a control sample of pristine unsized fibre, was measured and is presented in Table 1 .

Using the broad definitions of hydrophilic $\left(\mathrm{WCA}<90^{\circ}\right)$ and hydrophobic (WCA $90-150^{\circ}$ ), we can see that pristine unsized carbon fibre is hydrophobic with a WCA of $98.4 \pm 0.6^{\circ}$. This may be anticipated, considering that the surface of carbon fibre is reported to consist of graphitic crystals, with some oxidized species from electrolytic oxidation performed during manufacture. ${ }^{45}$ Carbonaceous surfaces are more hydrophilic than expected, but are easily contaminated when exposed to air, via adsorption of hydrophobic species. Liu et al. showed this by measuring the WCA of graphene within 1 minute of exfoliation and after exposure to the open atmosphere for 2 days, the measured WCAs were substantially different being $59.6^{\circ}$ and $94.6^{\circ}$, respectively. ${ }^{46}$

Considering the open air manufacturing process of carbon fibres and that no atmospheric restrictions were placed on these samples, it is logical to assume they would possess a similar WCA to that reported to the aged graphene samples. Introduction of the nitrophenyl species, generating Surface 1, has a drastic effect on the contact angle, increasing it by approximately $25^{\circ}$ to $123.1 \pm 0.2^{\circ}$. Subsequent reduction of the aryl nitro species (Surface 2 ) reduces this back to $99.9 \pm 0.4^{\circ}$, very similar to that of pristine fibres. Similarly, the mixed functional groups present in Surface 3, showed a contact angle of $135.5 \pm 0.2^{\circ}$, and subsequent reduction of the nitrophenyl groups to the hydrogen bonding capable $\mathrm{NH}_{2}$ moieties (Surface 4) corresponded to a more hydrophilic surface, with a WCA to $119.3 \pm 0.3^{\circ}$.

Finally, examination of Surface 5, showed the second highest contact angle of this series of $134.4 \pm 0.2^{\circ}$, again an expected result considering that only fluorinated species have been attached to this surface.

Table 1 Water contact angle for pristine and treated fibres

\begin{tabular}{lrl}
\hline Sample & \multicolumn{1}{c}{ WCA $^{a}$} & Surface chemistry \\
\hline Pristine & $98.4 \pm 0.6^{\circ}$ & Graphitic/carbonaceous \\
Surface 1 & $123.1 \pm 0.2^{\circ}$ & $\mathrm{C}_{6} \mathrm{H}_{4}-\mathrm{NO}_{2}$ \\
Surface 2 & $99.9 \pm 0.4^{\circ}$ & $\mathrm{C}_{6} \mathrm{H}_{4}-\mathrm{NH}_{2}$ \\
Surface 3 & $135.5 \pm 0.2^{\circ}$ & $\mathrm{C}_{6} \mathrm{H}_{4}-\mathrm{NO}_{2} / \mathrm{C}_{8} \mathrm{H}_{4} \mathrm{~F}_{13}$ \\
Surface 4 & $119.3 \pm 0.3^{\circ}$ & $\mathrm{C}_{6} \mathrm{H}_{4}-\mathrm{NH}_{2} / \mathrm{C}_{8} \mathrm{H}_{4} \mathrm{~F}_{13}$ \\
Surface 5 & $134.4 \pm 0.2^{\circ}$ & $\mathrm{C}_{8} \mathrm{H}_{4} \mathrm{~F}_{13}$ \\
Surface 5 & $139.9 \pm 1.0^{\circ}$ & $\mathrm{C}_{8} \mathrm{H}_{4} \mathrm{~F}_{13}$
\end{tabular}

${ }^{a}$ Determined using $3 \mu \mathrm{L}$ of deionized water, the value and standard deviation reported is the average contact angle measured each second over 30 seconds. ${ }^{b}$ Measured using a different section of the same fibre sample. 
Raman mapping of carbon fibres has shown the surface heterogeneity of $\mathrm{sp}^{2} v s . \mathrm{sp}^{3}$ carbons to be quite high, and the electrochemical functionalization process used in this report is fundamentally linked to this heterogeneity. Therefore, it was of interest to determine how homogeneous the surface modification is over different sections of the same sample. Thus we measured the WCA on an alternate portion of the fibres for Surface 5 and monitored any changes over a period of 5 minutes. In this instance, a higher contact angle of $139.9 \pm 1.0^{\circ}$ was observed and was consistent at this WCA over the period of measurement.

At this point, all data suggests that the organic groups attached to the fibre surface are strongly bound, thus overcoming the first of the limitations supported by $\mathrm{Si}$ and Gao et $a l .{ }^{21}$ In order to test the resistance of these fibres to corrosive environments, alkaline $(9 \mathrm{M} \mathrm{NaOH})$, acidic $(12 \mathrm{M} \mathrm{HCl})$, and tap water solutions were dropped on a tow of Surface 5 (Fig. 6) and left for several minutes to get a qualitative measure of surface resistance to corrosive conditions. All solutions were all reasonably tolerated by the fibres, while organic solvents (petroleum spirit, methanol, etc.) were readily absorbed by these fibres. This indicates that the fibres may be suitable for application in highly corrosive environments, with inclusion of an appropriate resin (Videos of water resistance are provided in the ESI $\dagger$ ).

To highlight the effect surface chemistry can have on the functionality of carbon fibres, an example of separating a water/ chloroform mixture using these fibres is presented in the ESI. $\dagger$ It is worth noting that this was done as a demonstration only and quantitative measure of separation efficiency and residual solvent has not been conducted.

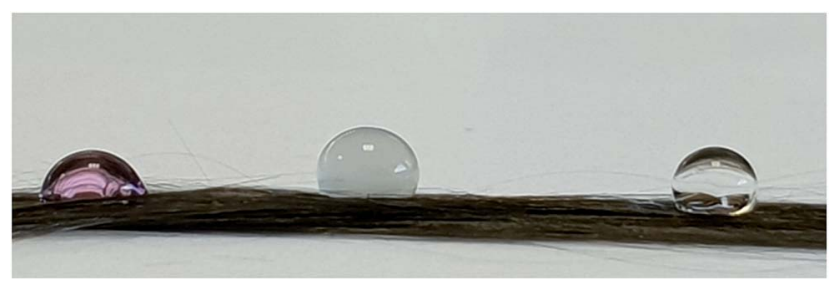

Fig. 6 Image showing the hydrophobic nature of the carbon fibres, labels refer (left to right) to: $9 \mathrm{M} \mathrm{NaOH}$ (with phenolphthalein indicator), $12 \mathrm{M} \mathrm{HCl}$, neutral (tap) water.

\section{Mechanical properties and interfacial adhesion of pristine and functionalised fibres}

It is crucial that any treatment which is applied to carbon fibres does not have any deleterious effects on their physical performance parameters, and of highest priority is tensile strength, and Young's modulus. These are indeed the properties of carbon fibres which have made them so desirable in many structural applications. Therefore, the tensile strength and Young's modulus of each surface chemistry explored herein was determined, at the single filament level, using a minimum of 60 filaments per sample to ensure high reproducibility and to minimize error.

Encouraging results saw that relative to the pristine fibres, no changes in tensile strength were observed for the treated fibres, with the exception of Surface 5 that showed a slight improvement over pristine fibres (Table 2, $4.03 \pm 0.10 \mathrm{GPa} v s$. $3.75 \pm 0.07 \mathrm{GPa}$, respectively). When examining the Young's modulus of these fibres, all the surface modified carbon fibres showed statistically significant increases relative to pristine fibres $(P<0.01)$. This has been observed in some cases in our previous work, ${ }^{20}$ and has historically been attributed to the removal of surface defects during the functionalization process and highlights another potential benefit of this treatment strategy (Table 2).

The preservation (and improvement with respect to Young's modulus) is critical to the success of this treatment protocol and enhances its appeal for carbon fibre producers to employ. As deterioration of these performance parameters would severely limit potential applications for these fibres.

Examination of the Weibull modulus values $(\mathrm{m})$, used to gauge defect formation, shows that the largest variation relative to pristine fibres is Surface 1 (Table 2, 7.03 and 4.54, respectively). This change is small, and consistent with our previous works, suggesting that there has been negligible defects introduced to the fibre surface. As carbon fibre behaves according to 'the weakest link in the chain' model, the introduction of surface defects can lead to substantial decreases in tensile strength. As no decrease in tensile strength was observed for these (or any) fibre it was considered that this electrochemical functionalisation process preserves the inherent properties of the carbon fibres.

Similarly, the scale parameter $\sigma$, is used to gauge the homogeneity of surface treatments. In this instance the variation across all the surface treated fibres was very small (3.994.38), suggesting a homogeneous treatment of the fibre surface.

Table 2 Fibre physical properties and Weibull parameters

\begin{tabular}{lllll}
\hline Surface & Tensile strength $(\mathrm{GPa})$ & Young's modulus $(\mathrm{GPa})$ & Weibull modulus $(m)$ & Shape parameter $(\sigma)$ \\
\hline Pristine & $3.75 \pm 0.07$ & $262.0 \pm 0.73$ & 7.03 & 3.99 \\
$\mathbf{1}$ & $3.72 \pm 0.09$ & $268.9 \pm 2.17^{a}$ & 4.54 & 3.98 \\
$\mathbf{2}$ & $3.86 \pm 0.09$ & $271.1 \pm 0.91^{a}$ & 5.37 & 4.20 \\
$\mathbf{3}$ & $3.67 \pm 0.08$ & $271.4 \pm 1.25^{a}$ & 5.71 & 4.02 \\
$\mathbf{4}$ & $3.88 \pm 0.10$ & $272.9 \pm 1.14^{a}$ & 6.05 & 4.20 \\
$\mathbf{5}$ & $4.03 \pm 0.10^{a}$ & $275.5 \pm 0.99^{a}$ & 6.18 & 4.38
\end{tabular}

${ }^{a}$ Denotes statistically significant change relative to pristine fibres $(P<0.01)$. 
This is logical as the solution in which the fibres are functionalised is a homogeneous solution and (at least on a macroscale) no single area of the fibres are more likely to be functionalised than another. Thus, a consistent surface treatment and coverage would be expected using this electrochemical protocol.

In the interest of thoroughness, we also conducted SEM imaging of the fibres to ensure that no physical pitting or notching was obvious on the fibre surface. Representative images of both pristine fibre and Surfaces 1-5 (Fig. 7) are provided. All of these show the typical surface morphology expected from carbon fibres, with grooves running along the axis of the fibre, arising from the wet-spinning process of the PAN precursor. This observation is consistent with our previous electrochemical treatments of carbon fibre (more images at a higher magnification $(15000 \times)$ are given in ESI $\dagger)$.

\section{Determination of interfacial shear strength}

Finally, the interfacial shear strength (IFSS) for fibres consisting of Surfaces 1-5 was determined using an epoxy thermoset resin (Fig. 8), as is consistent with our previous work. ${ }^{20}$ The determination of IFSS was carried out using the single-fibre fragmentation test (SFFT) which has been widely used in the literature and is commonly used within our group, and so provides an excellent basis for comparison to previous results. ${ }^{16-18,20,47-49}$ To provide context to these results, the IFSS values of these fibres were compared to unsized and unfunctionalised fibres (control, Fig. 8) which has a poor IFSS of $18 \pm$ $1 \mathrm{MPa}$. Surface 1, possessing layers of nitrophenyl species,
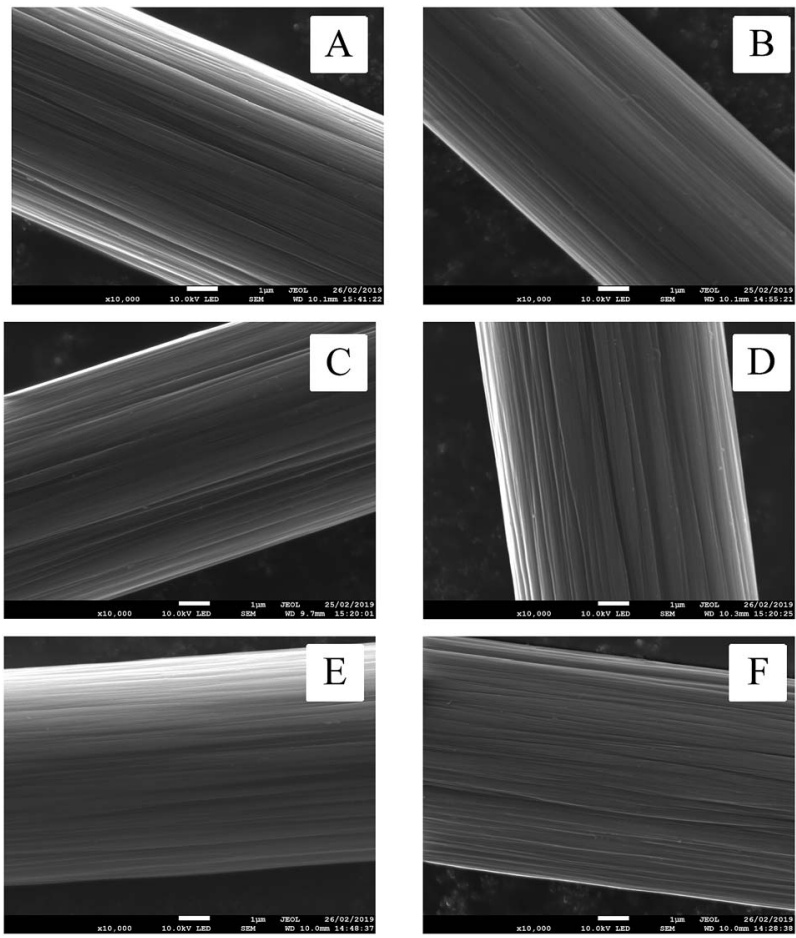

Fig. 7 Representative SEM of functionalised fibres showing no damage after treatment; (A) pristine; (B) Surface 1; (C) Surface 2; (D) Surface 3; (E) Surface 4; (F) Surface 5. All images are at $10000 \times$ magnification, white bars represent $1 \mu \mathrm{m}$.

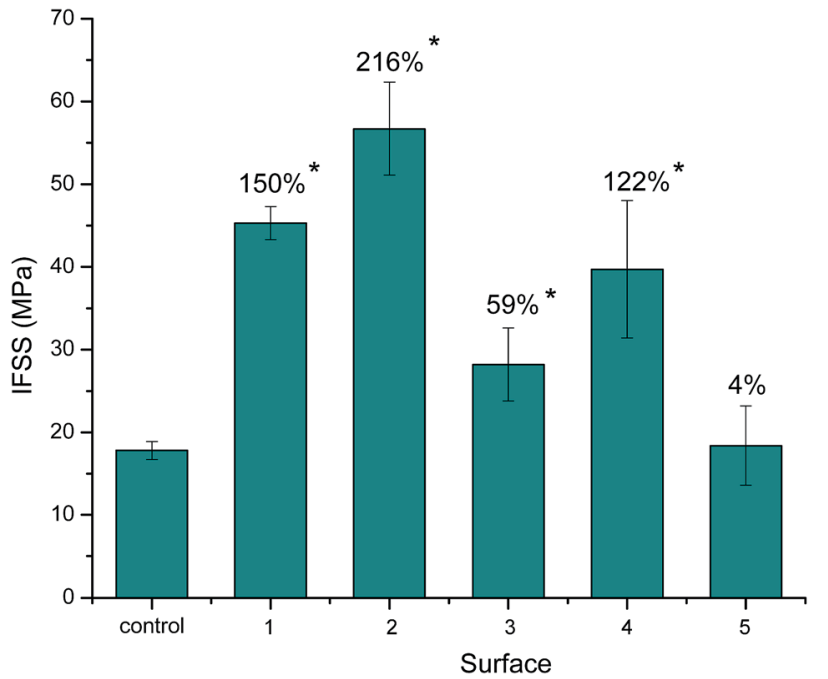

Fig. 8 IFSS for treated and pristine fibres. *Denotes statistically significant change relative to control $(P<0.01)$.

showed an enhanced IFSS of $45 \pm 2 \mathrm{MPa}$, constituting a $150 \%$ increase relative to the control fibres. This was further improved when these nitro groups were reduced to the corresponding amino groups (Surface 2) giving an IFSS of $57 \pm 5 \mathrm{MPa}$, a $216 \%$ improvement. This is consistent with our previous observations, whereby the penetration of rigid aryl groups into the interphase is enough to increase IFSS (as with Surface 1), though the introduction of reactive nitrogen moieties should facilitate the crosslinking of the fibres to the epoxy thus inducing further improvements in IFSS. ${ }^{20}$

Introduction of the mixed chemistry surface of nitroaryl and perfluorinated species (Surface 3), resulted in an improved IFSS of $28.2 \pm 2 \mathrm{MPa}(+59 \%)$, relative to the control sample, though this was markedly reduced relative to the nonperfluorinated analogue ( $c f$. 90\% difference), Surface 1. This may be explained by considering the 'dilution' of rigid phenyl groups attached to the surface by introducing the perfluorinated chains. Nevertheless, as observed previously, the reduction of the nitrophenyl species to the aminophenyl nitrogen (Surface 4) gave an improvement in IFSS of $40.3 \pm$ $8 \mathrm{MPa}(+122 \%)$, relative to control fibres. The ability to deconvolute the exact contributions from the polar and nonpolar components of the surface chemistry and their contribution to the IFSS increases is not possible. However, a general trend can be drawn when comparing Surface 1 and Surface 3, which possess aryl nitro and aryl nitro/perfluoro groups, respectively. In this instance the difference in IFSS increase is 91\% with Surface 1 being superior. Considering the similarity in preparation of each surface chemistry this difference must be attributable to the installation of the perfluorinated species. Similarly, comparison of the IFSS increase for Surfaces 2 and 4 show a 94\% difference, again with the nonperfluorinated surface being the better performing. Again, the non-polar surface functionalities have influenced the IFSS increase by a similar amount. Interestingly, Surface 5, possessing purely perfluoronated species, showed an unchanged 
IFSS relative to the control fibre of $17.8 \pm 5 \mathrm{MPa}$. While the IFSS of Surface 5 is comparable to that of the control fibres, it is worth noting that these fibres possess improved tensile strength and Young's modulus in addition to resistance to highly acidic, basic, and neutral aqueous solutions. This result may seem contrary to the previous observations regarding polar $v s$. non-polar contributions to IFSS, but in this instance Surface 5 has the alkyl chains directly added to the fibre surface and not tethered to the multi-aromatic structure deposited via the nitro aryldiazonium salt $\mathbf{4}$. The effect of this small multi-layered aromatic foundation encourages the protrusion of the perfluorinated groups in Surfaces 1, 2, 3, and 4 into the polymer phase, increasing 'drag' effects under shear. This effect is not present in Surface 5 and thus may be contributing to the minimal IFSS improvements. These interfacial effects are examined and discussed later using molecular dynamics simulation. Therefore, the IFSS gains when comparing Surface 4 and Surface 5 must be attributable to the polar and reactive points on Surface 4 , able to cross-link with the epoxy resin, and not the perfluorinated species which may serve to detract from the IFSS.

It is important to note that the ability of the surface modified fibres to be effectively 'wet-out' by the epoxy is inherent in the improved IFSS. If the fibres were to resist encapsulation by the epoxy resin then a poor interfacial interaction would result, and manifest as low adhesion under shear. As a demonstration of fibre-epoxy interaction a simple video and representative SEM images are provided in the ESI. $\dagger$ Future investigations of adhesion to these fibres will revolve around the use of fluorinated polymers that are used extensively in optoelectronics, oil and gas transport, marine, and biomedical applications. ${ }^{50-52}$

\section{Examination of the fibre surface by TEM}

Given the vast differences in chemical properties with respect to wetting and adhesion it was of interest to interrogate the surface of the fibres using high-resolution imaging and chemical mapping techniques. This process would allow at least qualitative determination of the coverage homogeneity and overall amount of fluorinated species on the surface of the fibres. As such, correlative transmission electron microscopy (TEM) and electron energy loss spectroscopy (EELS) were carried out on a cross-section of carbon fibre Surface 5 prepared by focused ion beam (FIB) milling (see Experimental section for details). Fig. 9 shows an overlay of EELS elemental maps for carbon (green) and fluorine (red), obtained by scanning transmission electron microscopy (STEM). A diagonal interface can be seen that divides the image from the bottom left to the top right, which is a thin, Pt deposition layer used to protect the surface of the fibre during FIB preparation (see Experimental section). The carbon fibre cross-section, indicated by the bright green signal, occupies the top left part of the image with its surface following the diagonal interface.

The bottom right part of the image indicates faint signal from $\mathrm{C}$ because the deposition material applied during the FIBbased preparation (both the thin, ion beam deposited layer, and the thick, electron beam deposited layer - see Experimental
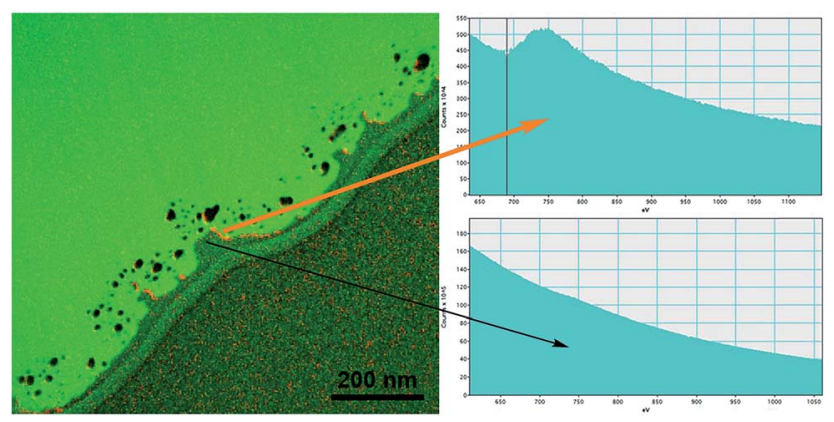

Fig. 9 EELS elemental map of the cross-section of fibre Surface 5 showing the distribution of carbon (green) and fluorine (red), with associated spectra correlated to local regions along the surface indicated by arrows.

section) is created from a precursor gas composed of both Pt and $\mathrm{C}$.

Dark spots near the surface of the fibre are holes in the specimen as a result of the manufacturing process, confirmed through both bright-field TEM imaging and EELS thickness mapping. The red signal belonging to fluorine was only detected in small amounts and observed to be localized, non-uniform and discontinuous along the fibre surface.

\section{Molecular dynamics simulations of the functionalized carbon fibre-epoxy interface}

Given the large improvements observed for interfacial shear strength, molecular dynamics (MD) simulations were performed of the functionalised fibre-matrix interface. This was carried out to predict the conformational preferences of the chemically-attached species on the fibre surface in the presence of the matrix and to predict the interfacial shear stress (ISS) (which is one contributor to the IFSS). ${ }^{37,38}$

The ISS values were based on the change in total potential energy as a function of fibre pull-out. Details of the computational procedure are provided in ESI. $\dagger$

First predicted was the probability distribution of the vertical distance between the substrate surface and the nitrogen atoms in the distal nitro and amino groups for Surface $\mathbf{1}$ and 2, in the presence of the liquid precursor mixture prior to cross-linking of the polymer matrix (Fig. 10a). The simulation data suggests that the distal nitrophenyl group on Surface 1 was directed outwards from the surface, towards the liquid polymer mixture, such that an extended conformation was preferred (Fig. 10c, denoted herein as Config. ii). However, it was noted that a second likely conformation indicating a folded configuration (denoted Config. i). This conformation may be stabilized by substantial interactions between the nitro group and graphitic substrate (Fig. 10b).

On the other hand, the corresponding functional moiety that featured the aminophenyl group on Surface 2 (as opposed to the nitrophenyl group on Surface 1) was only found in an extended conformation that was directed away from the surface and towards the matrix (i.e. only in Config. ii). 
(a)

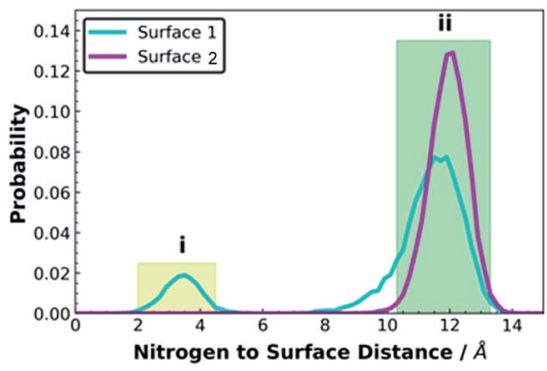

(b)

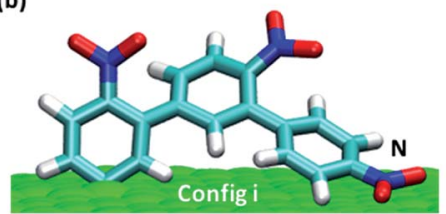

(c)

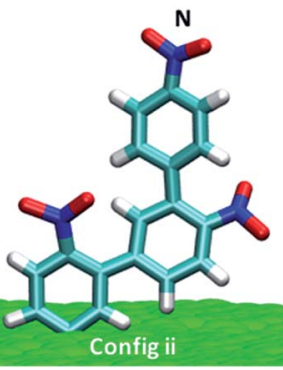

Fig. 10 (a) Predicted probability distribution of the vertical distance between the substrate surface and the nitrogen atoms (indicated as N) in the distal nitrogen site (Surface 1) and amine (Surface 2) groups. (b $\&$ c) Two likely conformations of the grafted molecules on Surface 1 in the presence of liquid precursor mixture (prior to initiation of crosslinking). Colour scheme: green, cyan, red, blue and white indicate surface carbon atoms, carbon, oxygen, nitrogen and hydrogen atoms of the grafted molecule, respectively.

These simulations can be compared with the STM images obtained on graphene and HOPG that show (at low surface coverage) isolated bushes of nitrophenyl groups standing up on the graphitic substrate. ${ }^{53}$

To summarize, the attached surface groups were more likely to be found in a fully extended conformation for Surface 2, compared with Surface 1. Our previous work has indicated that a high likelihood of extension of the surface grafted molecules into polymer matrix can reinforce the fibre-tomatrix interface with respect to shear, which has been shown to be consistent with a reinforcement of the composite as a whole. ${ }^{37}$

One additional difference between Surface 1 and Surface 2 is the reactivity of the surface grafted molecules towards the polymer matrix. The amino groups on Surface 2 are able to chemically react with the polymer matrix (Fig. 11a), while the nitro groups on Surface 1 are unreactive with respect to the formation of covalent bonds with the polymer matrix, and could interact only via soft interactions (e.g. non-bonded interactions such as van der Waals interactions). Our previous simulation work has indicated that covalent bonds between surface-grafted molecules and the polymer matrix can also confer greater reinforcement of the fibre-to-matrix interface compared with a fibre-matrix interface that is mediated via soft interactions only. Taken together, these differences can explain the greater ISS values predicted for Surface 2 compared with those predicted for Surface 1, an increase of $\sim 125 \%$ (Fig. 11b).

The comparisons and conclusions drawn from the simulations of Surfaces $\mathbf{1}$ and $\mathbf{2}$ are similar to those made for the
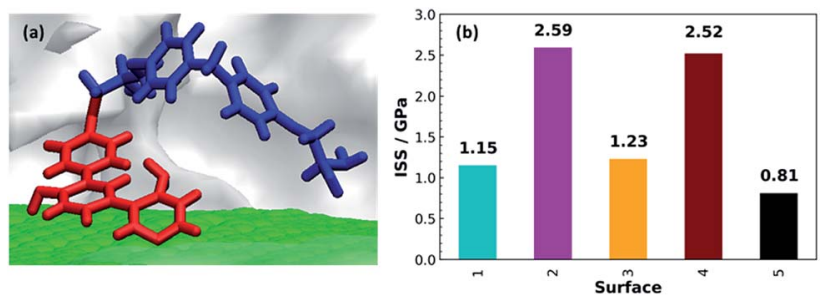

Fig. 11 (a) Molecular-level snapshot of an amino-phenyl group (red) chemically cross-linked with an epoxy (EPON) unit (blue) on Surface 2 (green). The rest of the polymer matrix is indicated as a white cloud. (b) Predicted interfacial shear stress (ISS) values for all treated fibres.

perfluorinated alkyl treated surfaces (i.e. Surfaces 3 and 4). In addition, the perfluorinated alkyl chain connected to the upper phenyl ring on Surfaces 3 and 4 exhibited somewhat different conformational behaviours on both surfaces (summarized in the ESI $\dagger$ ). For instance, although the distal carbon atom of the $\mathrm{CF}_{3}$ group for both Surfaces 3 and $\mathbf{4}$ was predicted to be most likely situated at a distance of $\sim 6 \AA$ from the substrate surface, the probability of this conformation was slightly higher on Surface 3 compared with Surface 4 . This could be explained by the fact that the distal nitro groups in a folded configuration can facilitate the extension of the perfluorinated alkyl chains such that they are directed away from the substrate surface. Our predicted ISS values showed a $\sim 105 \%$ increase for Surface 4 compared to Surface 3.

Finally, the computational investigation of the conformational distribution of surface grafted molecules on Surface 5 in the presence of liquid polymer mixture was performed (Fig. 12a). Our simulation results suggest that the perfluorinated alkyl chains preferred a folded conformation such

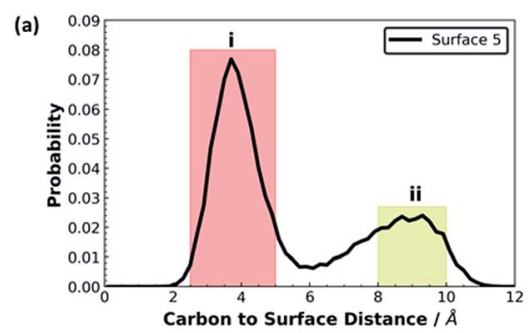

(b)

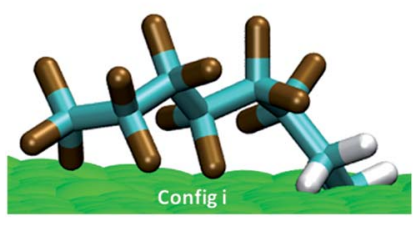

(c)

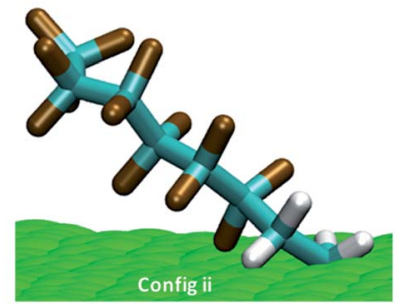

Fig. 12 (a) Predicted probability distribution of the vertical distance between the substrate surface and the carbon atoms in the distal $\mathrm{CF}_{3}$ group (Surface 5). (b and c) Examples of the two most likely conformations of the surface grafted molecules on Surface 5 in the presence of the liquid precursor mixture. Liquid precursor is not shown for clarity. Colour scheme: green, cyan, brown and white represent the surface carbon atoms, carbon, and fluorine and hydrogen atoms of the surface grafted molecule, respectively. 
that the chain was in close contact with the surface, in a relatively flat orientation with respect to the fibre surface (Fig. 12b). In addition, a partially extended conformation was also predicted to be present (albeit with a lower probability, Fig. 12c). Surface 5 was also unreactive towards the polymer matrix. Taken together, these can explain why the ISS (and the IFSS) of this surface was the lowest among the five surfaces investigated here.

\section{Conclusions}

This work demonstrates the ability to covalently modify the surface of carbon fibres through electrochemical reduction of diazonium radicals, as confirmed by XPS, IRATR, and TEM. The surfaces produced are highly hydrophobic, though this may be mitigated through the reduction of nitro groups to amines or increased through the accumulative effects of perfluoroalkyl chains and nitro groups (WCA up to $135.5 \pm 0.2^{\circ}$ ).

The hydrophobic fibres functionalized only with perfluoroalkyl groups were stable to both strongly acidic and strongly basic solutions. No fibre types of the five surfaces showed any reduction in fibre properties (tensile strength and Young's modulus), nor showed any visual evidence of deterioration from treatment when analysed by SEM. All surface chemistries demonstrated an increase in IFSS (up to 216\%) and these correlated well with calculated values of ISS, determined via molecular dynamics simulations. These simulations also served to predict the reactivity of amine moieties of the modified surfaces, as well as the orientation of these structures in relation to the fibre surface. It is the balance of these polar cross-linking interaction, inherent in the aryl amino moieties, and the non-polar perfluorinated groups that is critical to the combination of IFSS increase and hydrophobicity observed herein, respectively.

The findings of this study dispel the common misconception of increased fibre wettability amounting to an increase in composite strength and provides a rapid method of installing surface functionality that facilitates adaptation of carbon fibres for new applications.

\section{Conflicts of interest}

There are no conflicts to declare.

\section{Acknowledgements}

The authors gratefully acknowledge Deakin University and the Australian Research Council (ARC) (DP140100165, DP18010094) for funding this project. This research was conducted by the ARC Training Centre for Lightweight Automotive Structures (IC160100032) and the ARC Research Hub for Future Fibres (IH140100018) funded by the Australian Government. This work was funded in part by the Office of Naval Research (N62909-181-2024), which is gratefully acknowledged. We are grateful to A. Chevillot-Biraud and P. Decorse (ITODYS, Université Paris Diderot) for the TGA and XPS analysis. Deakin University's Advanced Characterisation Facility is acknowledged for use of the dual-beam FIB-SEM, and STEM-EELS instruments. CNRS, Paris Diderot University, and ANR (Agence Nationale de la Recherche) and CGI (Commissariat Général à l'Investissement) are gratefully acknowledged for their financial support of this work through Labex SEAM (Science and Engineering for Advanced Materials and devices). BD and TRW thank the National Computational Infrastructure and the Pawsey Supercomputing Centre for access to supercomputing resources. The authors also thank Solvay Composite Materials for the PhD scholarship for CA.

\section{Notes and references}

1 E. Mäder, K. Grundke, H. J. Jacobasch and G. Wachinger, Composites, 1994, 25, 739-744.

2 M. Sharma, S. Gao, E. Mäder, H. Sharma, L. Y. Wei and J. Bijwe, Compos. Sci. Technol., 2014, 102, 35-50.

3 F. R. Jones, J. Adhes. Sci. Technol., 2010, 24, 171-202.

4 S. Ben, J. Zhao, Y. Zhang, Y. Qin and T. Rabczuk, Compos. Struct., 2015, 129, 8-26.

5 C. Wang, X. Ji, A. Roy, V. V. Silberschmidt and Z. Chen, Mater. Des., 2015, 85, 800-807.

6 K. K. C. Ho, A. F. Lee and A. Bismarck, Carbon, 2007, 45, 775784.

7 L. Y. Yuan, C. S. Chen, S. S. Shyu and J. Y. Lai, Compos. Sci. Technol., 1992, 45, 1-7.

8 C. Scheffler, E. Wölfel, T. Förster, C. Poitzsch, L. Kotte and G. Mäder, IOP Conf. Ser.: Mater. Sci. Eng., 2016, 139, 012046.

9 N. Dilsiz, J. Adhes. Sci. Technol., 2000, 14, 975-987.

10 A. Fukunaga and S. Ueda, Compos. Sci. Technol., 2000, 60, 249-254.

11 M. R. Alexander and F. R. Jones, Carbon, 1994, 32, 785-794.

12 S. Yumitori and Y. Nakanishi, Composites, Part A, 1996, 27, 1051-1058.

13 S. Yumitori and Y. Nakanishi, Composites, Part A, 1996, 27, 1059-1066.

14 M. Nardin and J. Schultz, Compos. Interfaces, 1993, 1, 177192.

15 M. Delamar, G. Desarmot, O. Fagebaume, R. Hitmi, J. Pinson and J. M. Savant, Carbon, 1997, 35, 801-807.

16 K. M. Beggs, L. Servinis, T. R. Gengenbach, M. G. Huson, B. L. Fox and L. C. Henderson, Compos. Sci. Technol., 2015, 118, 31-38.

17 L. Servinis, K. M. Beggs, T. R. Gengenbach, E. H. Doeven, P. S. Francis, B. L. Fox, J. M. Pringle, C. Pozo-Gonzalo, T. R. Walsh and L. C. Henderson, J. Mater. Chem. A, 2017, 5, 11204-11213.

18 D. J. Eyckens, L. Servinis, C. Scheffler, E. Wolfel, B. Demir, T. R. Walsh and L. C. Henderson, J. Mater. Chem. A, 2018, 6, 4504-4514.

19 J. D. Randall, D. J. Eyckens, L. Servinis, F. Stojcevski, L. A. O'Dell, T. R. Gengenbach, B. Demir, T. R. Walsh and L. C. Henderson, Carbon, 2019, 146, 88-96.

20 L. Servinis, K. M. Beggs, C. Scheffler, E. Wölfel, J. D. Randall, T. R. Gengenbach, B. Demir, T. R. Walsh, E. H. Doeven, P. S. Francis and L. C. Henderson, Carbon, 2017, 118, 393403. 
21 Y. Si and Z. Guo, Nanoscale, 2015, 7, 5922-5946.

22 D. Nyström, J. Lindqvist, E. Östmark, P. Antoni, A. Carlmark, A. Hult and E. Malmström, ACS Appl. Mater. Interfaces, 2009, 1, 816-823.

23 T. Darmanin, E. T. de Givenchy, S. Amigoni and F. Guittard, Adv. Mater., 2013, 25, 1378-1394.

24 X. Zhang, D. Zhi, L. Sun, Y. Zhao, M. K. Tiwari, C. J. Carmalt, I. P. Parkin and Y. Lu, J. Mater. Chem. A, 2018, 6, 357-362.

25 A. R. Siddiqui, R. Maurya and K. Balani, J. Mater. Chem. A, 2017, 5, 2936-2946.

26 Y. Lu, S. Sathasivam, J. Song, C. R. Crick, C. J. Carmalt and I. P. Parkin, Science, 2015, 347, 1132-1135.

27 J.-J. Li, Y.-N. Zhou and Z.-H. Luo, Prog. Polym. Sci., 2018, 87, 1-33.

28 C. Peng, Z. Chen and M. K. Tiwari, Nat. Mater., 2018, 17, 355360.

29 S.-L. Gao, E. Mäder and S. F. Zhandarov, Carbon, 2004, 42, 515-529.

30 D. Hetemi, F. Kanoufi, C. Combellas, J. Pinson and F. I. Podvorica, Langmuir, 2014, 30, 13907-13913.

31 D. Hetemi, H. Hazimeh, P. Decorse, A. Galtayries, C. Combellas, F. Kanoufi, J. Pinson and F. I. Podvorica, Langmuir, 2015, 31, 5406-5415.

32 S. Plimpton, J. Comput. Phys., 1995, 117, 1-19.

33 W. G. Hoover, Phys. Rev. A: At., Mol., Opt. Phys., 1986, 34, 2499-2500.

34 S. Nosé, J. Chem. Phys., 1984, 81, 511-519.

35 W. G. Hoover, Phys. Rev. A: At., Mol., Opt. Phys., 1985, 31, 1695-1697.

36 S. L. Mayo, B. D. Olafson and W. A. Goddard, J. Phys. Chem., 1990, 94, 8897-8909.

37 B. Demir, L. C. Henderson and T. R. Walsh, ACS Appl. Mater. Interfaces, 2017, 9, 11846-11857.

38 B. Demir and T. R. Walsh, Soft Matter, 2016, 12, 2453-2464.
39 K. M. Beggs, J. D. Randall, L. Servinis, A. Krajewski, R. Denning and L. C. Henderson, React. Funct. Polym., 2017, 129, 123-128.

40 L. Lee, P. A. Brooksby, P. Hapiot and A. J. Downard, Langmuir, 2016, 32, 468-476.

41 H. Lu, D. Zeysing, M. Kind, A. Terfort and M. Zharnikov, J. Phys. Chem. C, 2013, 117, 18967-18979.

42 J. R. Lomeda, C. D. Doyle, D. V. Kosynkin, W.-F. Hwang and J. M. Tour, J. Am. Chem. Soc., 2008, 130, 16201-16206.

43 C. A. Dyke and J. M. Tour, Chem.-Eur. J., 2004, 10, 812-817.

44 M. Toupin and D. Bélanger, J. Phys. Chem. C, 2007, 111, 5394-5401.

45 N. Dilsiz and J. P. Wightman, Colloids Surf., A, 2000, 164, 325-336.

46 Z. Li, Y. Wang, A. Kozbial, G. Shenoy, F. Zhou, R. McGinley, P. Ireland, B. Morganstein, A. Kunkel, S. P. Surwade, L. Li and H. Liu, Nat. Mater., 2013, 12, 925.

47 F. Stojcevski, T. B. Hilditch, T. R. Gengenbach and L. C. Henderson, Composites, Part A, 2018, 114, 212-224.

48 C. L. Arnold, K. M. Beggs, D. J. Eyckens, F. Stojcevski, L. Servinis and L. C. Henderson, Compos. Sci. Technol, 2018, 159, 135-141.

49 K. M. Beggs, M. D. Perus, L. Servinis, L. A. O'Dell, B. L. Fox, T. R. Gengenbach and L. C. Henderson, RSC Adv., 2016, 6, 32480-32483.

50 F. Babudri, G. M. Farinola, F. Naso and R. Ragni, Chem. Commun., 2007, 1003-1022.

51 A. Vitale, R. Bongiovanni and B. Ameduri, Chem. Rev., 2015, 115, 8835-8866.

52 S. Ribeiro, T. Ribeiro, C. Ribeiro, D. M. Correia, J. P. S. Farinha, A. C. Gomes, C. Baleizão and S. LancerosMéndez, Polymers, 2018, 8, 933.

53 J. Greenwood, T. H. Phan, Y. Fujita, Z. Li, O. Ivasenko, W. Vanderlinden, H. Van Gorp, W. Frederickx, G. Lu, K. Tahara, Y. Tobe, H. Uji-i, S. F. L. Mertens and S. De Feyter, ACS Nano, 2015, 9, 5520-5535. 